revista ANTHROPOLÓGICAS

Ano 24, 31(2): 153-179, 2020

\title{
Construindo Infraestrutura para as Elites: Os grandes condomínios da Barra e um novo modelo de se morar na cidade
}

Rodrigo Cerqueira Agueda ${ }^{a}$

\begin{abstract}
A Barra da Tijuca ganhou protagonismo no cenário habitacional do Rio de Janeiro a partir dos anos 70, principalmente no âmbito das classes altas. Desde os fatores que precederam essa emergência, passando pelo processo de construção do bairro como alternativa, de sua ocupação e ressignificações, até um presente (e futuro) do que o bairro representa como lugar de moradia e de sua relação com a cidade, a investigação desse processo e de seus reflexos concretos nos fornece um novo panorama para se pensar a produção da cidade e o desenvolvimento urbano do Rio de Janeiro. Busco com este artigo trazer o objeto dos 'condomínios-cidade' da Barra da Tijuca para se pensar esse desenvolvimento urbano recente da cidade, focando no protagonismo que as infraestruturas urbanas têm nesse processo.

Condomínio, Barra da Tijuca, Infraestrutura, Elites.
\end{abstract}

A Barra da Tijuca ganhou protagonismo no cenário habitacional do Rio de Janeiro a partir dos anos 70, principalmente no âmbito das classes altas. Desde os fatores que precederam essa emergência, passando pelo processo de construção do bairro como alternativa, de sua ocupação e ressignificações, até um presente (e futuro) do que o bairro representa como lugar de moradia e de sua relação com a

a Doutorando do Programa de Pós-graduação em Sociologia (IESP-UERJ). Email: rodrigoagueda@iesp.uerj.br. 
cidade, a investigação desse processo e de seus reflexos concretos nos fornece um novo panorama para se pensar a produção da cidade e o desenvolvimento urbano do Rio de Janeiro. Os grandes condomínios do bairro, que aqui chamarei de 'condomínios-cidade' na tentativa de os diferenciar de outros modelos de habitação similares, servem como uma porta de entrada para o exame desse fenômeno que tomou conta do bairro, nos permitindo uma inserção nos cotidianos e nas relações que os envolvem, a partir da qual poderemos pensar sobre reflexos concretos sob a ótica dos que vivem nesses locais. A emergência desses condomínios, junto dos conflitantes imaginários e estilos de vida que os acompanham, nos permitem refletir sobre o papel das infraestruturas urbanas nas relações sociais e na produção do espaço, nos apresentando uma nova perspectiva para se pensar moradia, urbanização, violência e desigualdade.

Caso empírico para se entender processos recentes de transformações urbanas assim como os imaginários, anseios e modos de vida das camadas médias e das elites, os grandes condomínios residenciais da Barra da Tijuca, e em especial os 'condomínios-cidade', possibilitam um olhar atento a dois aspectos relevantes em torno das infraestruturas: a relação entre o urbanismo e as infraestruturas urbanas, entre o planejamento e o funcionamento (ou não) das materialidades e subjetividades dessas - já que as singularidades do processo de urbanização do bairro inserem uma temporalidade distinta da conjuntura do 'eternamente em obras' associada às outras partes da cidade; e a questão da desigualdade, aqui não nos termos mais comuns da literatura que foca na dicotomia norte global versus sul global, mas em uma desigualdade interna da cidade, cujas infraestruturas - pelas promessas, pela oferta e/ou pelo funcionamento - são um forte indicador.

\section{'Condomínios-cidade’}

Primeiramente, cabe uma breve explicação do que estou chamando de 'condomínios-cidade'. O fenômeno das gated communities de 
forma mais geral, assim como os seus mais diversos reflexos mundo afora, é estudado por diversas frentes e possui eixos centrais que aproximam todos os exemplos desse novo modelo de moradia, e que nos são úteis também para compreender o caso específico que se deu no Rio de Janeiro. Esse fenômeno tem suas raízes nos Estados Unidos, representando uma espécie de 'nova camada de suburbanização', quando os clássicos subúrbios brancos e ricos passaram a se tornar cada vez mais diversificados (Vesselinov \& Le Goix 2012) e, desde então, vêm se espalhando pelo mundo como alternativa das classes altas em uma busca por segurança, homogeneidade e status (Blakely \& Snyder 1997; Low 2001). Como fenômeno global, suas mais diversas variações têm cada uma suas especificidades, que vão desde as edge cities californianas (Garreau 1991), aos barrios cerrados e islas urbanas (Roitman 2011) latino-americanas. No Brasil, os exemplos de modelos de moradia têm sido estudados em termos dos condomínios fechados, de forma mais geral, ou em uma perspectiva de 'enclaves fortificados' (Caldeira 200), que incluem formas não exclusivamente de moradia. Classificá-los por suas especificidades, portanto, se faz necessário, de modo a "problematizar a utilização de conceitos e modelos construídos a partir de casos específicos para compreender outros problemas também específicos" (Patriota de Moura 2010:209). Os 'condomínioscidade' da Barra da Tijuca são exemplos do fenômeno de autossegregação das elites, da contenção da vida em espaços demarcados e de uma rejeição aos aspectos clássicos das cidades modernas. Trazem em si traços dos 'enclaves fortificados' que Caldeira (2000) analisa em São Paulo, assim como evocam imagens semelhantes aos 'condomínios horizontais' de Patriota de Moura (2012). Possuem, porém, fatores que os diferem desses outros exemplos e que, portanto, produzem uma forma de sociabilidade diferente, um novo estilo de vida que muda o cotidiano da cidade do Rio de Janeiro de forma mais ampla. Compreendê-los dentro de um fenômeno global, mas a partir de suas especificidades é essencial para entender a particularidade da Barra da Tijuca. 
Pensando o espaço dos 'condomínios-cidade' a partir da noção trazida por Santos como "um conjunto indissociável, solidário e também contraditório de sistemas de objetos e sistemas de ações, não considerados isoladamente, mas como o quadro único no qual a história se dá" (2012:63) é imprescindível para que possamos examinar todo o complexo de objetos, ações e agentes que existem e circulam por esses empreendimentos, sempre partindo da relação entre eles. Nos permite enxergá-los não apenas como um local onde coisas acontecem, mas como as coisas em si tanto quanto o local onde elas acontecem. Em outras palavras, nos permite pensar como um fenômeno, como um recorte espaço-temporal da vida.

O termo 'condomínio' é aqui trazido não pelo seu sentido formal, como compartilhamento de posse ou bem, mas no sentido nativo dos moradores da cidade, que parece apontar para algo como um local de moradia de grande dimensão compartilhado por muitas unidades familiares e que possuem espaços compartilhados de convivência e serviços. Esse sentido excluiria prédios únicos, ou prédios que compartilham apenas de uma mesma guarita ou estacionamento, o que é essencial para uma análise que coloca em destaque a parte da convivência. Já o termo 'cidade' que trago diz respeito à relação dialética que tais empreendimentos possuem com a cidade, tanto em seu sentido mais figurativo quanto em relação ao espaço urbano concreto do Rio de Janeiro. Nessa relação, os primeiros são pensados, moldados e vivenciados a partir de um contraponto e uma oposição à cidade, em uma tentativa de criar um distanciamento e uma autossegregação autossuficiente, ao mesmo tempo que eles constituem um importante fenômeno urbano, criado a partir das representações da cidade e cujos efeitos moldam, em grande parte, o desenvolvimento contemporâneo e as relações cotidianas do Rio de Janeiro. Além disso, ao mesmo tempo que se baseiam em imaginários de oposição ao ideal de uma cidade moderna, investindo na promessa de sossego, segurança e homogeneidade contra a incerteza, violência e confusão da cidade, há a tentativa de construir uma ideia de que o condomínio 
é quase uma cidade, com possibilidade de lazer, trabalho e moradia, além do tamanho por si só, das praças e locais de convivência, das ruas internas e dos diversos serviços, essenciais para se falar em autossuficiência. Idealizados por seus criadores como 'bairros planejados', eles possuem características muito mais associadas ao imaginário de cidade do que ao imaginário do bairro, compreendendo diversos círculos de sociabilidade, uma heterogeneidade interna, divisão de espaços e quase que todos os tipos de serviços em seu interior, atendendo aos anseios mais variados A coexistência de espaços públicos e privados nesses locais, e a consequente incorporação privada de um espaço legalmente público, que é um traço primordial desses condomínios, é um exemplo dessa dialética contraditória, que inclui o embate entre o público e o privado. Essa intrínseca contradição, que produz, desde os primeiros anúncios desses empreendimentos, uma coexistência de imaginários 'antiurbanos' com imaginários de abundância de controle, serviços e possibilidades, resulta na confusão que faz com que autores enxerguem a Barra da Tijuca como a 'anticidade carioca' (Sánchez 2009) mesmo ela sendo um dos principais motores das transformações urbanas contemporâneas da cidade e dos investimentos públicos e privados. A condição essencialmente dialética dos 'condomínios-cidade' é o que nos permite compreender o bairro pela forma com que ele tem sido simbolicamente construído, não por um eixo ou outro, mas pela coexistência antagônica dessas duas extremidades. A síntese dessa dialética seria o que aqui proponho como objetivo de investigação, a vida que é gerada a partir desse novo modelo de se viver, o novo cotidiano e a nova relação com a cidade que emergem junto a esses grandes empreendimentos.

Uma tentativa, talvez ainda não totalmente satisfatória, de estabelecer uma definição para os 'condomínios-cidade', precisaria incluir alguns elementos. A grande extensão territorial, a autossegregação, que pode se dar por diversas maneiras, mas, em especial, por meios simbólicos ${ }^{1}$, a ideia de autossuficiência, um aparato privado de segurança e a coexistência de espaços públicos e privados são elementos 
essenciais. Esses fatores fazem desse tipo de empreendimento algo único, com causas e efeitos singulares que estruturam um modo de vida novo. Eles criam uma diferenciação de cotidianos na cidade que ilustra uma nova fase na vida das elites e camadas médias cariocas, que teve início tanto a partir do êxodo das elites tradicionais da Zona Sul quanto da 'emergência' dos 'novos ricos' advindos principalmente da Zona Norte. Com eles podemos criar uma diferenciação com os 'enclaves fortificados' de Caldeira (2000), que são espaços privados no meio do centro urbano, não necessariamente de residência, e que têm os muros como principal mecanismo de separação com o exterior, assim como dos 'condomínios horizontais' de Patriota de Moura (2012), que são exclusivamente de casas e não necessariamente trazem a ideia de cidade ou de autossuficiência. São uma expressão do fenômeno das gated communities, se organizam como common-interest developments (CID), mas trazem singularidades de um bairro modernista em meio a um território de milícias, um laboratório de experimentação de um paraíso urbano (Gorelik 2000 apud Balthazar 2020) pensado para as elites, mas que assume um 'ethos emergente' (Lima 2007), um palco de grandes eventos e da grilagem de terras que assume o papel de global suburb (Herzog 2013) em uma cidade do sul global.

\section{Novo Leblon pelos jornais}

A reflexão aqui proposta parte do âmbito de uma pesquisa em andamento, em que pesquiso as transformações urbanas recentes da cidade do Rio de Janeiro (RJ) no que tange à expansão da malha urbana em direção ao bairro da Barra da Tijuca, localizado na Zona Oeste, seguindo o caminho da orla do mar. Como o foco é na parte da urbanização que segue 'o caminho da orla do mar', a pesquisa gira em torno da ocupação da região voltada para as elites, o que na segunda metade do século XX significava, em grande medida, a emergência dos grandes condomínios residenciais. Portanto, a pesquisa se baseia em uma coleta de material de jornais das décadas de 1960 a 1980, 
principalmente relacionados a um dos principais exemplos desse tipo de empreendimento inovador que seriam os 'condomínios-cidade': o Condomínio Novo Leblon.
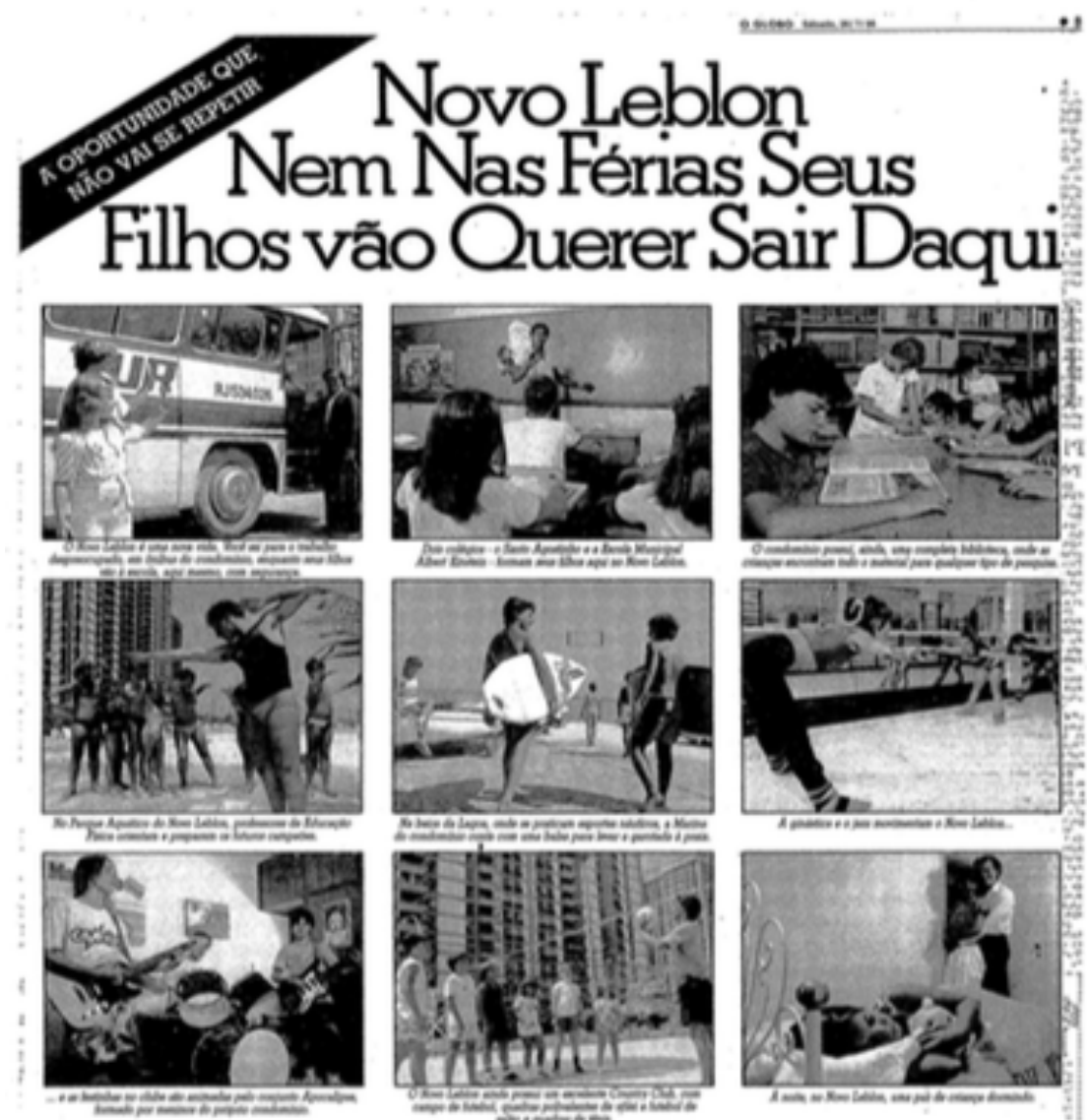

E Não São so as Criancas Que Gostam deViver Aqui...
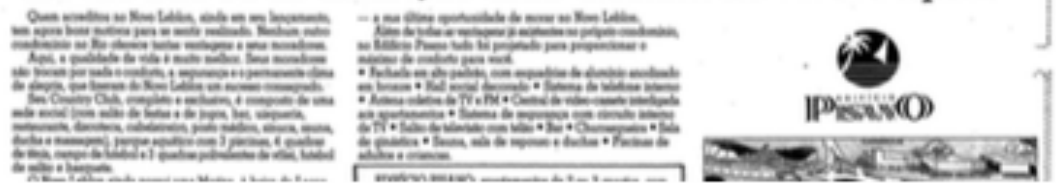

Imagem 1: Fonte Acervo do Jornal ‘O Globo’, 26/07/1986. 


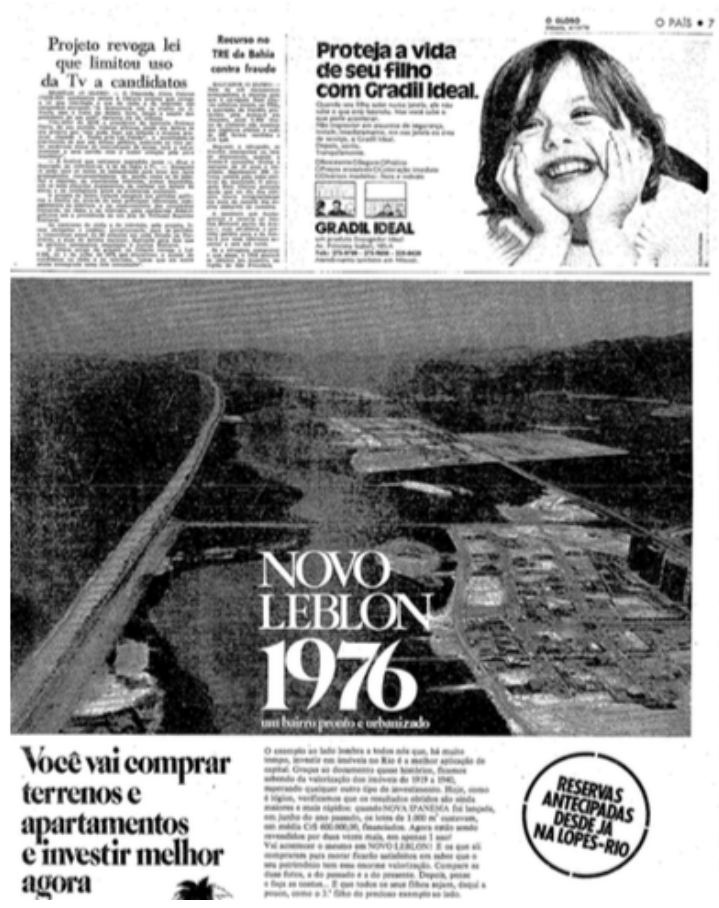

Imagem 2: Fonte: Acervo do Jornal 'O Globo', 04/12/1976.

O Condomínio Novo Leblon, que por muito tempo fora o maior empreendimento residencial da cidade, possui diversas características que fazem dele um objeto interessante de análise, e que muito nos diz sobre a construção material e simbólica do bairro e o modo de vida que o segue. Presente na ideia original do plano urbanístico desenhado por Lúcio Costa para a região, como um dos 'numerosos núcleos urbanizados ao longo da BR-101 [atual Avenida das Américas]' (Costa 1969), o condomínio atualmente possui os mais variados serviços, ligação direta com três shopping centers, duas escolas, um country club, diversas praças e áreas verdes em meio às oito torres de vinte andares e duzentos terrenos para casas. $\mathrm{O}$ material referente à sua construção, em especial as propagandas, aponta para essa contradição referente aos 'condomínios- 
cidade', simultaneamente se contrapondo à já muito urbanizada Zona Sul e seus problemas urbanos e prometendo todas as infraestruturas e serviços das grandes metrópoles. Contendo já em seu nome uma ideia de progresso em relação a um dos bairros mais elitizados da Zona Sul carioca, o Leblon, o condomínio tenta se contrapor à 'antiga Zona Sul' repetindo um mecanismo já utilizado na história urbana da cidade, de criação de um problema urbano para oferecer uma promessa de alternativa. O que primeiro foi feito em relação a Copacabana, repetindo os mesmos imaginários bucólicos e utópicos, é trazido a partir dos anos 60 para a Barra da Tijuca, dessa vez sob a égide do planejamento urbano modernista, tentando conciliar a promessa de futuro e do moderno a uma volta a um passado a-histórico, estabelecendo uma "ordem temporal de sucessivas repetições” (Balthazar 2020:92).

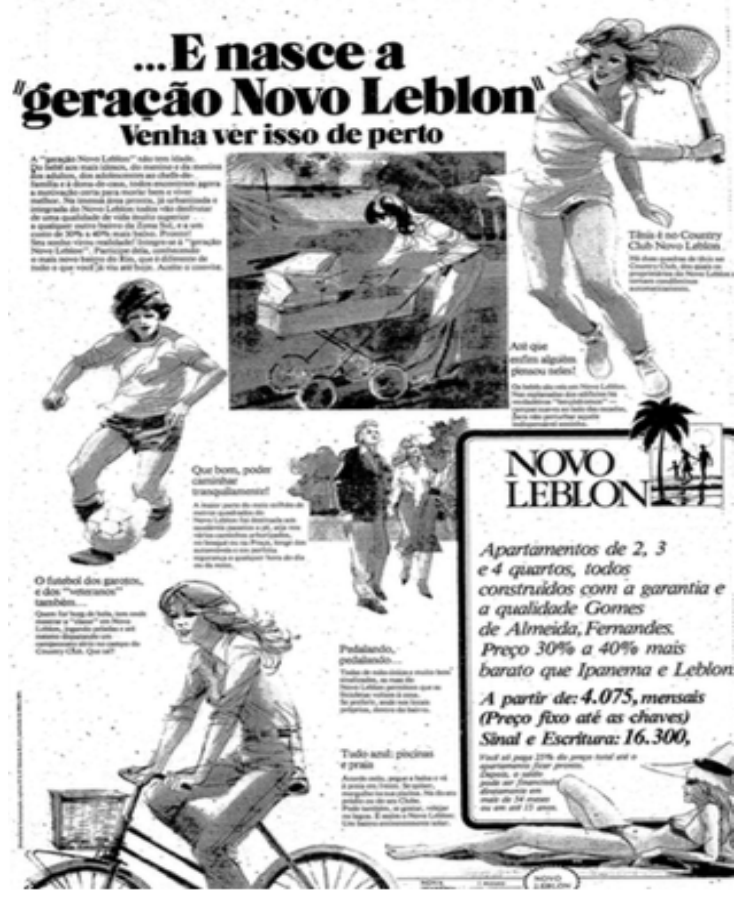

Imagem 3: Fonte: Acervo do Jornal 'O Globo', 15/01/1977. 


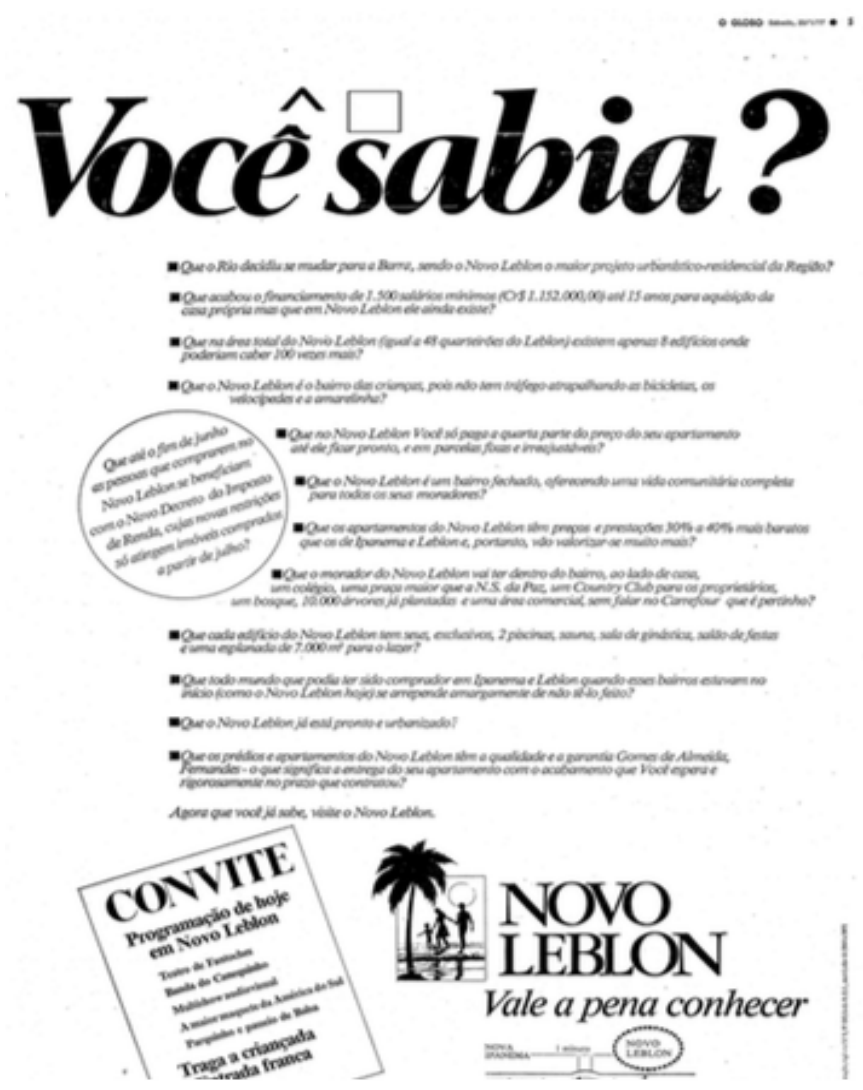

Imagem 4: Fonte: Acervo 'O Globo', 22/01/1977.

No material de 466 páginas analisadas do período entre 1960 e 1980, alguns aspectos ficam em evidência quanto aos imaginários evocados pelas construtoras, mídia e poder público acerca desses condomínios. Para além das ideias de autossuficiência e autossegregação, importantes para a construção do que viria a ser o estilo de vida 'barrense' - de negação do pedestre em prol dos automóveis e das largas avenidas, dos locais de encontro e de sociabilidade murados, privados e protegidos no lugar das praças públicas e da distinção e separação 
física entre classes - as promessas voltadas para as infraestruturas aparecem com frequência. Na tentativa de equilibrar a falsa dicotomia 'urbano não-urbano' que é promovida pelos anúncios, a possibilidade de uma vida 'afastada' em meio ao 'sertão carioca' depende do acesso aos serviços e comodidades dos centros urbanos. A menção a uma "infraestrutura urbana completamente pronta" (Jornal do Brasil 10/01/1976), ou a um "bairro pronto e urbanizado" (Jornal do Brasil 02/12/1976) que aparecem nas propagandas têm esse intuito, de garantir para as camadas médias e elites cariocas as mesmas comodidades que teriam nos bairros 'completamente urbanizados' da Zona Sul ou Zona Norte, mas sem os problemas que advém dessa urbanização e falta de planejamento. Tal comodidade vem a cargo do Estado, seja pelo fornecimento de água, de saneamento básico ou telefone, que aparecem constantemente nas páginas dos jornais enquanto as favelas que surgiam nas margens já nasciam também marcadas pelas infraestruturas, porém, pela sua ausência ou falha.

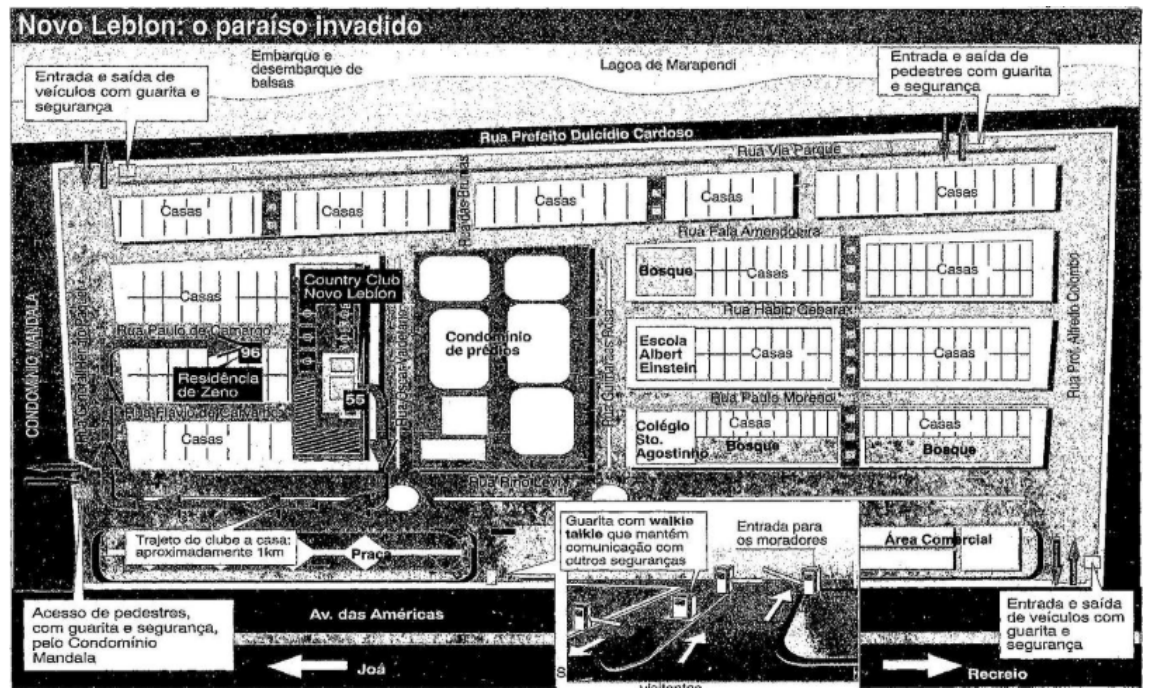

Imagem 5: Fonte: Acervo 'O Globo', 22/01/1995. 


\section{RIO}

\section{Nem condomínio intimida}

Beltrame manda investigar seqũestros-relâmpago dentro do Novo Leblon, na Barra
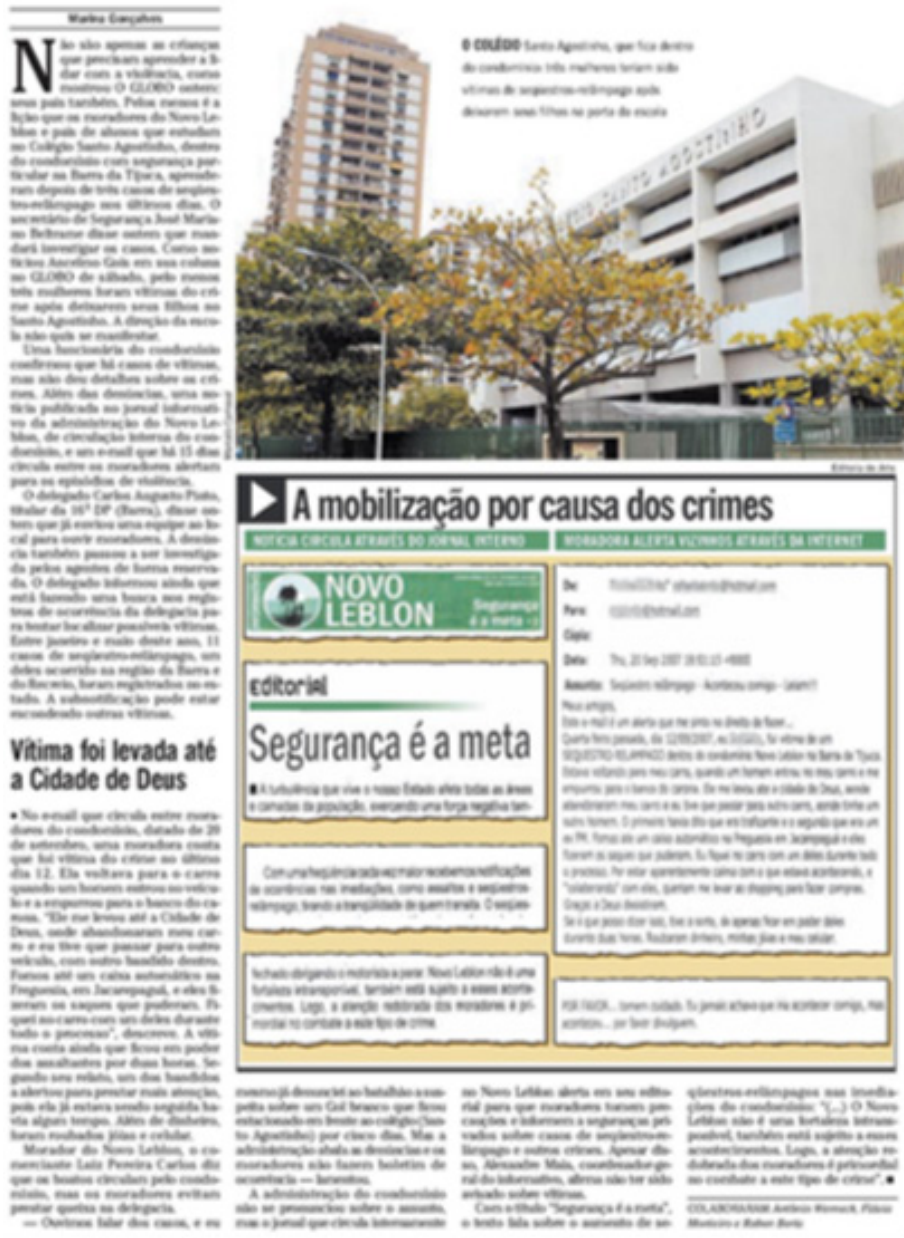

A violéncia wai onde a citima esté

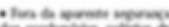

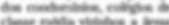

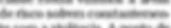

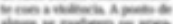

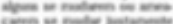

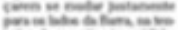

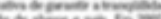
remeinis

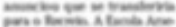

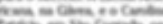

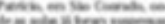

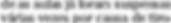

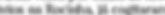

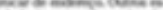

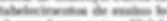

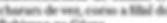

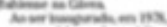

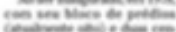

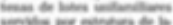

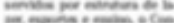

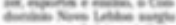

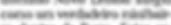

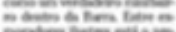

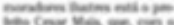

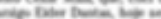
mis numatom itson inat to ore bin

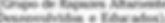

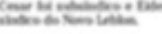

Imagem 6: Fonte: Acervo 'O Globo', 01/10/2007. 


\section{ESCAL_ADA DA VIOLENCLA \\ Casas de papel}

Roubos a residéncias aumentam 70\%; clima é de apreensăo em condominios da Barra
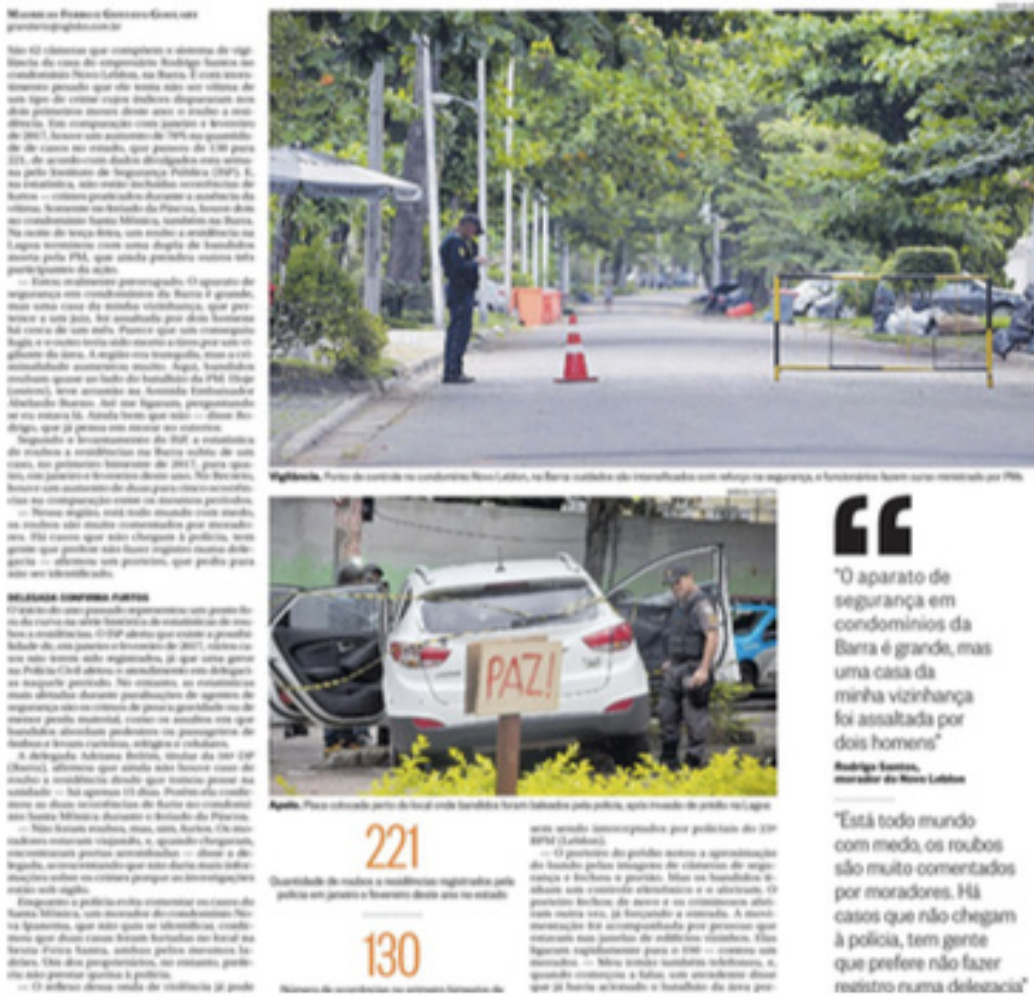

"O aparato de sepuranga em condominios da Bura erande mas umb casa ds michavirhanca for assakata por dois homens' netaseren

Tases tobo munds com meobs os rockes sbo multo comeressos por moradones. Hu casos que nbe chegem a polioa, tem gente que crefene ndo fave: revintio numa de levorid?

Imagem 7: Fonte: Acervo 'O Globo', 05/04/2018.

Sob a lente das infraestruturas

Uma abordagem interessante - e que o material empírico mostrou ser essencial - para buscar entender a construção material e simbólica da Barra da Tijuca e o fenômeno dos 'condomínios-cidade' e 
suas implicações na vida urbana é pensar sob a ótica das infraestruturas. De acordo com Brian Larkin:

"Infrastructures are built networks that facilitate the flow of goods, people, or ideas and allow for their exchange over space. As physical forms they shape the nature of a network, the speed and direction of its movement, its temporalities, and its vulnerability to breakdown. They comprise the architecture for circulation, literally providing the undergirding of modern societies, and they generate the ambient environment of everyday life." (Larkin 2013:328).

Essa definição nos permite inserir os condomínios no domínio das infraestruturas. Como uma grande infraestrutura, ou seja, uma forma física que possibilita a circulação de pessoas e ideias, a criação de redes, e condiciona a vida cotidiana, ou como um conjunto aglutinador de muitas outras infraestruturas. Nesse segundo sentindo, levando em conta o contexto histórico da emergência desse fenômeno no bairro que era retratado como 'sertão carioca', esses polos de urbanidade trouxeram as infraestruturas necessárias para a alocação das elites, para que uma vida urbana fosse possível. Não é à toa que uma das contrapartidas para a construção desses empreendimentos é que eles providenciassem o asfaltamento interno, postes de luz e uma escola pública. Os 'condomínios-cidade' traziam a infraestrutura de cidade para onde os efeitos da urbanidade não chegavam em seu sentido amplo. A ideia era trazer o 'lado bom' da cidade ao mesmo tempo que se afastava do 'lado ruim' da cidade. Considerando o primeiro sentido, como uma infraestrutura para além de um conjunto de infraestruturas, esses condomínios são "matter that enable the movement of other matter", ou seja, são coisas, mas também a relação entre coisas (Larkin 2013:329). São tanto uma estrutura física grandiosa em termos de paisagem quanto ideais e símbolos fluidos e a vida que se dá em seu interior. É um sistema de ações e objetos, determinador de rotinas. Essa grande infraestrutura se enquadra também na definição de Collier (2011), onde as infraestruturas seriam uma mistura de racionalidade política, técnicas administrativas e sistemas materiais 
(Larkin 2013:331). O trabalho conjunto do Estado e do capital imobiliário, que fez da Barra da Tijuca um grande canteiro de obras na década de 70, assim como a sustentação desse projeto e dos desejos por alternativas das famílias ricas da Zona Sul carioca pela grande mídia, inclui um emaranhado de técnicas administrativas, sistemas materiais e racionalidade política. Os condomínios aqui são as evidências físicas dessas práticas de governo, das relações capitalistas e das disputas de imaginários que se davam na cidade.

Essas grandes estruturas físicas refletem um embate de imaginários que molda o desenvolvimento urbano carioca, a busca por tranquilidade em uma cidade violenta, a busca por isolamento em um meio heterogêneo, a busca por simplicidade em uma cidade cada vez mais complexa. Vemos também a questão do futuro e da promessa como parte integrante do fenômeno dos 'condomínios-cidade', desde sua concepção pelo poder público até suas propagandas e no discurso de moradores. Os $82 \mathrm{~km}^{2}$ urbanizáveis da Barra da Tijuca, o 'eldorado urbano' (Leitão 1999) foi o palco para a criação de uma promessa de uma nova vida, para uma produção de desejos e possibilidades expressados nessas novas infraestruturas que cresciam em meio a restingas e mangues. Os grandes condomínios, carros-chefes da urbanização do bairro, "are critical both to differentiated experiences of everyday life and to expectations of the future" (Appel, Anand \& Gupta 2018:3), sendo um dos principais marcadores de desigualdades na Zona Oeste carioca. Como infraestruturas, simultaneamente escondem e expõem marcas da história, funções do presente e promessas de futuro. As marcas da história se mostram não apenas na arquitetura e nas propagandas, que mesmo sendo dos anos 80 já são antigas para o ritmo da cidade, mas também em contraste com as favelas da Zona Oeste mostrando as marcas do desenvolvimento urbano desigual da cidade. Revelam as "fragile and often violent relations between people, things and institutions that govern or provision them" (Appel, Anand \& Gupta 2018:3), marcadas por grilagem de terra e por remoções. 
A concepção dos 'condomínios-cidade' da Barra da Tijuca pela chave das infraestruturas nos coloca em uma posição interessante para se pensar em diversos aspectos da vida cotidiana. Isso porque a possibilidade de uma vida autossuficiente só se faz possível por meio das infraestruturas que esses empreendimentos abrigam. O saneamento, o asfalto sem buracos e com quebra-molas pintados, as câmeras de segurança que seguem cada movimento, os postes de luz que contribuem para a segurança em momentos 'desertos' da madrugada nesses condomínios de altas médias de idade, fazem com que uma vida tranquila 'funcione' ali dentro. Basta entrar no BRT, alguns passos à frente da entrada do condomínio, e em 5 minutos podemos encarar uma realidade das infraestruturas quase que oposta, onde o não funcionamento é o padrão - na mesma e multifacetada Zona Oeste. Essa desigualdade de expectativas molda o dia a dia dentro e fora dos condomínios. Desde o horário de sair de casa - que pode ser 1 minuto antes do horário fixo de saídas regulares dos ônibus privados do condomínio ou muito tempo antes para quem depende das filas e lotação dos BRTs ou ônibus com horários irregulares - passando pela programação de horário para sair e chegar em casa - que podem passar a qualquer horário para alguns ou apenas nas horas onde é seguro para outros - até a atenção ao dirigir - seja por conta dos quebra-molas ou dos buracos - e as gambiarras e gatos para garantir luz e internet em oposição aos geradores de energia, são detalhes do cotidiano que dependem do funcionamento ou não das infraestruturas. E são detalhes que contribuem para uma vivência desigual na cidade, que vai muito além das explícitas diferenças de bairros e de casas. Afinal, as infraestruturas servem não só como demarcadores de progresso e desenvolvimento, como também diferenciam populações e sujeitam alguns a uma 'morte prematura' (Fanon 1961; Gilmore 2007; McKittrick 2011 apud Appel, Anand \& Gupta 2018).

A chave do cotidiano tem uma importância ímpar em uma análise que tenha a vida como objeto, sendo a infraestrutura uma "integral and intimate part of daily social life". (Appel, Anand \& Gupta 
2018:6). O cotidiano nos coloca no âmbito intermediário (Martins 2008) entre o senso comum e a interpretação acadêmica, entre a superestrutura e a personificação de suas consequências. Ele é o híbrido, onde é possível, no micro reconhecer de divergentes manifestações do macro (Ribeiro 2005). É no estudo da vida cotidiana, na observação minuciosa do banal do dia a dia e do senso comum, que estão os significados compartilhados entre os sujeitos, sem os quais não existiria interação. (Martins 2008). Nesses significados compartilhados, nesse banal do dia a dia, nos 'gestos-fio' (Ribeiro 2005), buscamos investigar de que forma os condomínios afetam a maneira como as pessoas experimentam a cidade, de que maneira as infraestruturas urbanas interagem e modificam a vida das pessoas e como esse novo modelo de vida autossegregado e protegido representa uma nova face da desigualdade e da segregação urbana.

Partindo, então, de uma perspectiva do cotidiano e tendo as infraestruturas como um "new optical field through which we can examine the lived dimensions of urban society" (Chattopadhyay 2012 apud Addie Glass \& Nelles 2020:11), proponho uma abordagem etnográfica para o estudo dos 'condomínios-cidade'. Trazendo a etnografia menos como um método e mais como uma orientação (Roy 2012), o acompanhar do dia a dia nos possibilita enxergar como de fato os condomínios alteram a vida das pessoas, como elas utilizam e se relacionam com as infraestruturas e como circulam e se alteram os imaginários sobre a cidade. Como argumenta von Schnitzler (2015), a atenção nas infraestruturas é antropológica, por nos proporcionar um campo para repensar e desfamiliarizar o político (Appel, Anand \& Gupta 2018). O estudo sobre o Condomínio Novo Leblon, portanto, serve de exemplo para se entender a desigualdade e a temporalidade que as infraestruturas urbanas assumem em uma cidade como o Rio de Janeiro. A partir dessa investigação sobre a construção do Novo Leblon, podemos investigar o protagonismo que a promessa e falha das infraestruturas têm no estabelecimento de um desenvolvimento urbano desigual. 
Para além das promessas mais genéricas de um 'bairro completo' ou de uma 'infraestrutura completa' que se repete em diversos anúncios, ao lado das imagens de famílias sorrindo em meio a árvores e bosques, exemplos mais explícitos surgem como indicadores desse protagonismo exercido pelas infraestruturas no processo. $\mathrm{O}$ abastecimento de água, por exemplo, aparece como uma questão antes mesmo do início das propagandas do Novo Leblon. Uma matéria do dia 19 de janeiro de 1976, intitulada "Graça Couto assegura que a água não encarece imóveis da Barra e de São Conrado" (Jornal do Brasil 19/01/1976) demonstra a preocupação do Estado em garantir a promessa de água para os empreendimentos (privados) que surgiam. $\mathrm{O}$ engenheiro em questão aponta para o fato de que o abastecimento de água já era uma promessa do governo e estava no planejamento dos empreendimentos, e "na Barra, o abastecimento servirá sobretudo aos grandes conjuntos imobiliários em construção", mesmo com o concomitante crescimento de favelas na região, como a Cidade de Deus, que abrigava muitas das famílias removidas de favelas de outras regiões da cidade. A indicação, ainda na mesma matéria, de que "sem isso, nenhum dos projetos poderia ser inaugurado" e que os condomínios "deixarão de ser uma aventura, como são agora", aponta novamente para a indispensabilidade das infraestruturas para que todo esse processo de transformação urbana em direção à Barra da Tijuca fosse possível, e para que uma experiência urbana 'afastada' da cidade pudesse ser trazida como promessa. Uma matéria de março de 1979 relata que uma nova adutora construída com dinheiro federal já levava água até a "altura do conjunto Novo Leblon" (Jornal do Brasil 11/03/1979), enquanto uma outra do mês seguinte trazia a promessa do Secretário de Obras do Estado, Emílio Ibrahim, de que a água para a Barra era prioridade. Outras reportagens trazem também a questão dos 'carros-pipa' que mudaram seus planejamentos para focar no abastecimento do bairro já que "lá, nunca houve água" (Jornal do Brasil 24/04/1979), cujas grandiosas obras demandavam uma alta quantidade de água. Aqui, a água não só faz parte de um cotidiano futuro, 
como promessa de uma vida possível para alguns, mas faz parte também de cotidianos da época, influenciando nas redes de serviços, nas circulações e nos imaginários construídos acerca das diferentes 'zonas oestes' que surgiam simultaneamente.

Para além do abastecimento de água, outras infraestruturas aparecem nas reportagens com o mesmo intuito. Em janeiro de 1979, uma reportagem relata que "o gás de rua, que rompeu morros para vir do Leblon até a Barra [...] já chegou ao empreendimento Novo Leblon” (Jornal do Brasil 11/01/1979). Outra matéria traz já na manchete "Luz, gás, água, telefone e assistência médica. A cada dia ampliam-se e modernizam-se os serviços públicos do mais novo bairro da cidade" (Jornal do Brasil 29/09/1979). No mês seguinte matérias circulavam com a demanda por mais telefones residenciais e a rápida resposta de que mais seriam colocados à venda. Todas essas demandas e promessas que circulavam pelos jornais nos anos de 1978 e 1979 indicavam o poder que tais serviços e suas estruturas físicas detinham sobre um cotidiano imaginado dos condomínios. Ao imaginarmos essas muitas demandas dentro de um mesmo espaço, fechado para o resto da cidade, é possível inferir como um conjunto de infraestruturas possibilita a circulação de pessoas e vidas onde antes não era tido como viável. Por essas infraestruturas circulam também ideias e valores atrelados ao viver na Barra da Tijuca e ao viver dentro de um 'condomínio-cidade', que muito se diferenciam das experiências de outras áreas da cidade.

Um outro exemplo interessante para se pensar sob essa lógica é o ônibus privado desses condomínios, que saem regularmente com destino ao Centro e outros pontos da cidade por diversos trajetos e com diversos pontos para desembarque. Seus bancos reclináveis, acesso à internet e o ar condicionado permitem que os moradores vivam longe de seus locais de trabalho, mas continuem com fácil e confortável acesso a ele. No curto período em campo no Novo Leblon, interrompido pela pandemia do Covid-19, pude acompanhar e utilizar esse serviço, conferindo como essa infraestrutura afeta o cotidiano dos moradores. Passava diariamente ao lado do corredor do BRT, com seus ônibus 
lotados de pessoas espremidas, assim como as suas estações cheias de pessoas esperando a oportunidade de se encaixar no próximo que passar. Ao meu lado, passageiros dormiam, assistiam a séries, liam livros ou escutavam músicas, com suas mochilas e bolsas no banco ao lado. As buzinas, o incômodo do contato físico de estranhos e até o medo ficam do lado de fora. Outro exemplo é o fornecimento de luz. Nos últimos anos, os momentos de falta de luz na cidade do Rio de Janeiro, especialmente na Zona Oeste por consequência das chuvas e ventos, foram percebidos de maneiras diversas, já que as favelas não possuem os geradores que o Novo Leblon tem. As noites à luz de velas, sem ar condicionado ou televisão, se contrastam com as noites nos únicos prédios e casas iluminados da região. Esses exemplos mostram como a infraestrutura é essencial para a criação de uma bolha: um espaço demarcado onde a vida confortável é possível, em meio a territórios onde ela não o é. Assim como em 1976, em seu lançamento, o Novo Leblon trazia a urbanização para o 'sertão carioca', ele continua trazendo as infraestruturas necessárias para diferenciar a vida em seus muros, tornando o viver na cidade uma possibilidade para as elites e camadas médias que demandavam uma fuga da cidade com uma crescente violência urbana.

Voltando para o material de jornal, podemos ver exemplos concretos das ideias mobilizadas na época da construção do Novo Leblon que nos ajudam a entender a possibilidade de pensar neles sob a ótica das infraestruturas. A ideia de autossuficiência, que é marca da segregação e do aspecto de 'cidade' desses empreendimentos, é um dos pontos mais explorados pelas imobiliárias. Como mostra a Figura 1, a possibilidade de uma vida completa em um espaço determinado, que inclui vínculos sociais, lazer, esporte, educação e segurança, é um atrativo para aqueles que percebiam insegurança nos trajetos na cidade e na simples saída de casa. Já a Figura 2 ilustra o peso da chegada desse condomínio como portador de infraestrutura e urbanização. É possível ver tanto o impacto na paisagem até então 'não-urbanizada' quanto a importância dada a ideia de um 'novo bairro pronto e ur- 
banizado'. O imaginário de uma nova vida que é possível nesse novo modelo de moradia é trazido também no exemplo da Figura 3, que estampa como manchete da propaganda "e nasce a geração Novo Leblon”, que contribui para a ideia de progresso tanto quanto para as ideias de um novo modelo de vida e de um grupo social demarcado. Outros pontos são resumidos na Figura 4, que fala em "maior projeto urbanístico-residencial da região”, em uma área equivalente a 48 quarteirões do Leblon, em "bairro fechado" e "vida comunitária completa”, assim como bosques e 10.000 árvores plantadas, todos exaltando as características já mencionadas de um 'condomínio-cidade".

Ao inserirmos esses condomínios na discussão das infraestruturas, nos cabe tratar de um ponto chave na literatura decorrente do 'infraestructure turn' (Addie, Glass \& Nelles 2020) das últimas décadas: a falha. Como portadoras de progresso e desenvolvimento, as infraestruturas são, desde sua concepção, acompanhadas de expectativas e promessas. Nelas, aspirações são formadas, reformadas e performadas estando, ao mesmo tempo, sempre ameaçando quebrar e falhar (Appel, Anand \& Gupta 2018), especialmente no sul global, onde "ruination is a constant companion of infrasructure" (Appel, Anand \& Gupta 2018:6). Essa falha pode significar tanto uma quebra de expectativas como uma 'quebra física', produzindo ruínas. Em ambos os casos, a falha faz parte da vida dessas infraestruturas, é parte integrante da sua agência nas relações que interpõe. Pensando no presente objeto, os condomínios (e as infraestruturas que vêm com eles) prometem principalmente segurança, homogeneidade e tranquilidade. Essa promessa - explícita nas propagandas - encontra materialidade nas grades, nos bosques, nas câmeras. Mas o que acontece quando essas infraestruturas falham? No caso dos condomínios, as promessas fazem com que famílias mudem vidas e planejamentos. Mas a resposta à crescente demanda por segurança passa a não ser suficiente, quando alta concentração de moradias de classes altas se torna um alvo. Desde dezembro de 1979, a insegurança aparece nos jornais como um problema dos condomínios, exemplificada pela matéria "Insegurança 
nos condomínios: adeus ilhas de paz e tranquilidade" (Jornal do Brasil 26/12/1979). O condomínio Novo Leblon, mais especificamente, passou a ser alvo de roubos de carros e sequestro relâmpagos, registrados desde a década de 90. Como mostra o mapa da Figura 5, publicado no jornal em 1995, todo o aparato de segurança não foi suficiente para impedir os crimes. Desde então, reportagens tratando de crimes dentro do espaço dos condomínios têm sido recorrentes (Figuras 6 e 7). A falha da segurança faz com que a falha seja, na realidade, relativa à autossuficiência prometida. Sem a segurança, tudo que as infraestruturas prometiam criar, uma nova vida possível no interior desses empreendimentos, se desfaz. Essa falha das infraestruturas dos condomínios nos leva a refletir sobre as promessas que deixam de cumprir, e de que forma apontam para um novo movimento dessas classes. Nos leva a refletir, também, sobre a natureza da relação entre o crime e a violência, em seus índices concretos, e o medo da violência urbana. Enquanto Setha Low (2001) indicava, ao estudar as gated communities estadunidense, que não havia relação direta entre aumento do medo e aumento dos índices de violência urbana, Patriota de Moura nos alerta para a probabilidade do caso do Rio de Janeiro ser diferente, já que "no Brasil, os números referentes à violência urbana têm sido de fato cada vez mais alarmantes" (2012:35).

Tal falha deve, contudo, ser relativizada. De fato, as promessas que circundam tais empreendimentos envolvem fortemente as ideias de segurança e tranquilidade, e rapidamente dão indícios de não estarem atendendo às expectativas. Não à toa, no Novo Leblon, as discussões sobre os sistemas de controle de acesso aos condomínios seguem a todo vapor ainda hoje. Pensando a partir do ponto de vista nativo, a falha poderia também ser aquela relacionada à heterogeneidade existente e à vida prometida, que compreende não só os condomínios, mas a Barra da Tijuca toda, onde existe um forte sentimento contrário aos 'emergentes' ou 'farofeiros' que circulam pelo bairro, como aparece de forma recorrente nas redes sociais. A própria presença de uma escola pública dentro do Novo Leblon indica tal incômodo, já tendo 
recebido financiamento voluntário de moradores para que o espaço 'se encaixasse melhor' no condomínio. O que me parece interessante, porém, é pensar nas diferentes falhas que surgem na Zona Oeste, e de que forma elas indicam a relação das infraestruturas com a produção desigual da cidade.

As ruínas que circundam os condomínios que se alastram pela região afetam mais uns do que outros. É verdade que as ruínas do grandioso projeto de Oscar Niemeyer do Athaydeville ainda são presentes na paisagem da Barra da Tijuca, assim como ruas que levam a lugar nenhum são realidade no entorno de grandes condomínios da região da 'Barra Olímpica'. Mas são ruínas que impactam muito menos os moradores do Novo Leblon e de outros condomínios do que as ruínas que existem desde os anos de 1960 e que são alvo de reclamações dos moradores da Cidade de Deus. Dos muitos 'elefantes brancos' que surgem na cidade, não é por acaso que o que recebeu investimento para que deixasse de ser um 'elefante branco' foi o que se encontrava no meio da Barra da Tijuca - que veio a se tornar a Cidade das Artes. Muito mais do que nos fazer pensar sobre promessa e falha, as infraestruturas têm muito a nos dizer sobre as desigualdades dessas promessas e dessas falhas. Quando o protagonista do filme "Cidade de Deus" (2002) diz que "a filosofia do governo naquela época consistia no seguinte raciocínio: não tem onde pôr? Manda pra Cidade de Deus!", é difícil não comparar com as propagandas da mesma época que prometiam, a poucos quilômetros dali, uma vida completa e sossegada. Entender a relativa falta de segurança dentro dos condomínios como falha e o não-funcionamento de outras infraestruturas como regra já é um indício da desigualdade.

\section{Considerações finais}

Essas provocações têm como intuito apenas apresentar e indicar uma nova possibilidade de se pensar nas mudanças urbanas contemporâneas no Rio de Janeiro, assim como na segregação residencial na 
cidade e no lugar das infraestruturas urbanas nessas transformações. A discussão das gated communities já demostrou ser muito produtiva para se pensar em desigualdade e práticas das elites nos Estados Unidos, assim como tem servido de base para se pensar no urbanismo e nas culturas urbanas na América Latina. Acredito que os países do 'sul global' apresentam características que fazem com que os reflexos desse fenômeno nestes tome outras proporções, servindo de entrada para se estudar as diferentes relações urbanas que se dão nesses países, assim como a dinâmica específica de suas elites. Os 'condomínioscidade' da Barra da Tijuca são reflexo do desenvolvimento urbano carioca, das relações de classe e da disputa de imaginários acerca da cidade e da violência. As infraestruturas que esses empreendimentos trazem são a evidência física desses processos (Larkin 2013) e disputas, tanto na busca por elas quanto em suas falhas. A reflexão aqui proposta visa contribuir tanto para o estudo das infraestruturas urbanas quanto para a ideia de pensar nelas em termos regionais (Addie, Glass $\&$ Nelles 2020), assim como produzir material empírico para ampliar o estudo de modo de vida de elites e do fenômeno das gated communitites para outras cidades do 'sul global', permitindo um estudo global dos processos de transformações urbanas e de produção da cidade.

Parto de uma pesquisa em andamento que nos ajuda a entender a emergência de um bairro, de um modelo de moradia e de um estilo de vida e, portanto, nos fornece material para se pensar sobretudo nas promessas. Em termos de cotidiano, em que acredito que a influência das infraestruturas possa ser melhor compreendida, o estudo em questão apenas indica cotidianos possíveis, ou a construção deles, pouco nos auxiliando a pensar no seu desenvolver contemporâneo. Parte integrante da construção tanto material quanto simbólica da Barra da Tijuca e dos 'condomínios-cidade', a perspectiva das infraestruturas urbanas demanda uma continuidade do que foi feito até então. Considerando que a história da urbanização do Rio de Janeiro esteja desde seus primórdios apoiada em promessas e falhas, a fase recente, com suas muitas peculiaridades, merece uma maior atenção. 
$\mathrm{O}$ que a pesquisa em que o presente artigo se baseia procura oferecer, então, é um primeiro passo em direção a um estudo maior sobre as transformações urbanas e cotidianos que envolvem a Zona Oeste carioca, tendo como perspectiva o olhar atento às infraestruturas urbanas em suas desiguais composições. $O$ potencial analítico que a Barra da Tijuca nos oferece, como pertencente a essa 'entidade geográfica distinta' que é o Sul Global (Simone 2020) e ao mesmo tempo podendo ser compreendida como um global suburb (Herzog 2013) entre regiões de milícias e uma ampla orla marítima, é enorme. Os condomínios como forma urbana inédita da cidade, como locus de aglutinação de infraestruturas e sociabilidades, nos propicia um olhar inovador por 'olhar para cima' e pensar na produção do espaço pelas camadas altas. Por mais que a observação participante e estudos de caráter etnográfico acerca das elites possuam diversos entraves (Caldeira 2000; Khan 2012; Low 2001), eles são essenciais para que se possa ter uma melhor dimensão da desigualdade referente à 'vida' das infraestruturas, já que sem essa perspectiva de 'studying up' ( $\mathrm{Na}$ der 1972) ficamos restritos a apenas uma parcela dos cotidianos que constroem a cidade.

\section{Notas:}

${ }^{1}$ Os 'condomínios-cidade' da Barra da Tijuca também possuem artifícios como muros, grades e portões como divisores com o exterior. Porém, os meios simbólicos (ou pelo menos o aspecto simbólico desses artifícios físicos) é o que nos chama atenção. Shopping centers, portões desproporcionais, diferença das ruas e gramados entre o interior e o exterior, parecem ter uma relevância maior nessa separação, até porque esses espaços seriam de livre acesso.

\section{Referências:}

ADDIE, J.-P., GLASS, M. \& NELLES, J. 2020. "Regionalizing the infrastructure turn: a research agenda”. Regional Studies, Regional Science, 7(1):10-26. 
APPEL, H., ANAND, N. \& GUPTA, A. 2018. "Introduction: Temporality, Politics and the Promise of Infrastructure". In APPEL, H., ANAND, N. \& GUPTA, A. (eds.): The Promise of Infrastructure, pp.1-38. Durham: Duke University Press.

BALTHAZAR, A. C. 2020. "O tempo da Barra da Tijuca: Concepções de passado, presente e futuro na narrativa midiática sobre o bairro". Dilemas, Revista de estudos de Conflito e Controle Social, 13(1):77-94.

BLAKELY, E. \& SNYDER, M. G. 1997. Fortress America. Washington, DC: Brookings Institute.

CALDEIRA, T. 2000. Cidade de Muros - crime, segregação e cidadania em São Paulo. São Paulo: Editora 34/Edusp.

CHATTOPADHYAY, S. 2012. Unlearning the city: Infrastructure in a new optical field. Minneapolis: University of Minnesota Press.

CIDADE de Deus. 2002. Direção de Fernando Meirelles. Rio de Janeiro: Globo Filmes. 1 DVD (130 min.).

COLLIER, S. 2011. Post-Soviet Social: Neoliberalism, Social Modernity, Biopolitics. Princeton University Press.

COSTA, L. 1969. Plano Piloto para urbanização da baixada compreendida entre a Barra da Tijuca, o Pontal de Sernambetiba e Jacarepaguá. Rio de Janeiro: Agência Jornalística Image.

GARREAU, J. 1991. Edge City: Life on the New Frontier. New York: Anchor Books.

GORELIK, A. 2005. “A produção da 'cidade latino-americana”". Tempo Social, 17(1):111-133.

HERZOG, L. A. 2013. Barra da Tijuca: The Political Economy of a Global Suburb in Rio de Janeiro, Brazil. Latin American Perspectives, 40(2):118-134.

KHAN, S. 2012. "The Sociology of Elites". Annual Review of Sociology. 38:361-77.

LIMA, D. 2007. "Ethos 'emergente': As pessoas, as palavras e as coisas". Horizontes Antropológicos, 13(28):175-202.

LARKIN, B. 2013. "The Politics and Poetics of Infrastructure". Annual Review of Anthropology, 42:327-343.

LEITÃO, G. 1999. A construção do Eldorado Urbano: O Plano Piloto da Barra da Tijuca e Baixada de Jacarepaguá - 1970/1988. Niterói: EDUFF.

LOW, S. 2001. "The Edge and the Center: Gated Communities and the Discourse of Urban Fear". American Anthropologist, 103(*):45-58.

MARTINS, J. S. 2008. A sociabilidade do homem simples. São Paulo: Contexto.

NADER, L. 1972. "Up the Anthropologist: Perspectives gained from studying up”. In HYMES, D. (ed.): Reinventing Anthropology, pp. 284-311. New York: Pantheon Books.

PATRIOTA DE MOURA, C. 2010. "Condomínios e Gated Communities: por uma antropologia das novas composições urbanas”. Anuário Antropológico, II:209-233. . 2012. Condomínios no Brasil Central: Expansão urbana e antropologia. Brasília: Editora Universidade de Brasília. 
RIBEIRO, A. C. 2005. "Sociabilidade, hoje: leitura da experiência urbana". Caderno CRH, 18(45):411-422.

ROITMAN, S. 2011. "Distinción social y hábitat residencial en América Latina". Revista INVI, 26(73):17-71.

ROY, A. 2012. "Ethnographic circulations: space-time relations in the worlds of poverty management". Environment and Planning A, 44(1):31-41.

SÁNCHEZ, N. 2009. A invenção da Barra da Tijuca: a anticidade carioca. Dissertação de Mestrado. São Paulo: Universidade Presbiteriana Mackenzie.

SANTOS, M. 2012. A natureza do espaço: técnica e tempo, razão e emoção. São Paulo: Hucitec.

SIMONE, A. 2020. "Cities of the Global South". Annu. Rev. Sociol., 46:603-22.

VESSELINOV, E. \& LE GOIX, R. 2012. "From picket fences to iron gates: suburbanization and gated communities in Phoenix, Las Vegas and Seattle". GeoJournal, 77:203-222.

VON SCHNITZLER. 2013. "Traveling technologies: Infrastructure, ethical regimes, and the materiality of politics in South Africa". Cultural Anthropology, 28(4):670-693.

\begin{abstract}
Barra da Tijuca gained prominence in the housing scenario of Rio de Janeiro from the 1970s, mainly within the upper classes. From the factors that precede this emergency, through the process of building the neighborhood as an alternative, its occupation and reframing, to a present (and future) of what the neighborhood represents as a place of residence and its relationship with the city, an investigation of this process and of its concrete reflexes present us a new panorama to think the production of the city and the urban development of Rio de Janeiro. With this article we seek to bring the object of the 'city-condominiums' of Barra da Tijuca to think about that urban development of the city, focusing on the protagonism of the urban infrastructures in this process.
\end{abstract}

Keywords: Condominium, Barra da Tijuca, Infrastructure, Elites.

Recebido em setembro de 2020.

Aprovado em novembro de 2020. 